\title{
Retropharyngeal Spindle Cell/Pleomorphic Lipoma
}

\author{
Hyun Kyung Lee, $M D^{1}$, Seung Bae Hwang, $M D^{1}$, Gyung Ho Chung, MD ${ }^{1}$, Ki Hwan Hong, MD², \\ Kyu Yun Jang, $M D^{3}$ \\ Departments of ${ }^{1}$ Radiology, ${ }^{2}$ Otolaryngology-Head and Neck Surgery and ${ }^{3}$ Pathology, Chonbuk National University Medical School and Hospital, \\ Jeonju 561-712, Korea
}

Spindle cell/pleomorphic lipoma is an uncommon benign adipose tissue tumor most frequently arising from the subcutaneous tissue of the back, shoulder, head and neck, and extremities. The deep cervical spaces are the rarely affected locations. Herein we report on the imaging findings of spindle cell/pleomorphic lipoma involving the retropharyngeal space in an elderly woman.

Index terms: Spindle cell/pleomorphic lipoma; Retropharyngeal space; Neoplasms; Ultrasound; Computed tomography; Magnetic Resonance Imaging

\section{INTRODUCTION}

Spindle cell/pleomorphic lipoma, accounting for 1.5\% of all adipocytic neoplasms, is a type of benign lipogenic tumor composed of primitive CD34-positive spindle cells, floret-like multinucleated giant cells, and mature adipocytes $(1,2)$. Although it is usually reported as a subcutaneous mass in the neck, shoulder, or back, the involvement of other anatomic sites such as the pharynx, oral cavity, parotid gland, genital organs, and extremities has been reported $(3,4)$. Also, an intradermal origin of this tumor with a wider anatomical distribution has been described $(1$, $2,5)$. To the best of our knowledge, no case of spindle cell/

Received April 19, 2012; accepted after revision August 31, 2012. Corresponding author: Seung Bae Hwang, MD, Department of Radiology, Chonbuk National University Medical School and Hospital, 20 Geonji-ro, Deokjin-gu, Jeonju 561-712, Korea.

- Tel: (8263) 250-2308 - Fax: (8263) 272-0481

- E-mail: sbh1010@jbnu.ac.kr

This is an Open Access article distributed under the terms of the Creative Commons Attribution Non-Commercial License (http://creativecommons.org/licenses/by-nc/3.0) which permits unrestricted non-commercial use, distribution, and reproduction in any medium, provided the original work is properly cited. pleomorphic lipoma situated in the retropharyngeal space has been reported in English literature. We present here a case of spindle cell/pleomorphic lipoma occurring in the retropharyngeal space.

\section{CASE REPORT}

A 69-year-old woman initially presented with a 1-year history of painless swelling on both lateral sides of the neck, which was associated with mild dysphagia and dyspnea. The patient had a history of treatment with surgical and radiation therapies secondary to malignant schwannoma in the right neck about 25 years ago. Laryngoscopic examination revealed a bulging of the posterior hypopharyngeal wall with obliteration of bilateral pyriform sinuses, which suggested a retropharyngeal mass.

Ultrasonography (US) (iU 22 Ultrasound system, Philips Medical System, Bothell, WA, USA) of the patient demonstrated a large heterogeneous mass located in both lateral sides of the neck which was compressing the neck vessels laterally. The mass showed diffuse hyperechogenecity with multiple linear or band-shaped hypoechoic areas (Fig. 1A). A contrast-enhanced computed 

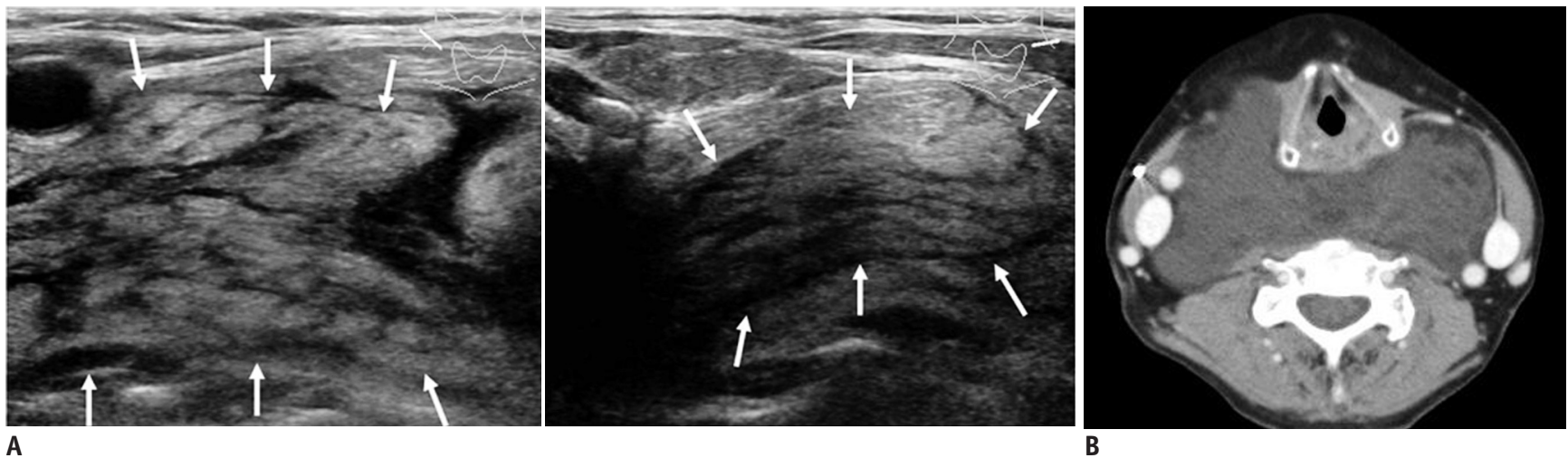

A

Fig. 1. Retropharyngeal spindle cell/pleomorphic lipoma in 69-year-old woman.

A. Ultrasonography (left: right side of neck, right: left side of neck) shows large heterogeneous mass (arrows) in both lateral sides of neck, and diffuse hyperechogenecity with multiple linear or band-shaped hypoechoic portions. B. Contrast-enhanced axial CT image shows huge and relatively well defined, minimal enhancing mass, including multifocal low attenuated areas (-15 to -40 Hounsfield unit). Mass is located in retropharyngeal space extending to both lateral sides of neck. Adjacent structures are displaced by tumor, with no evidence of invasion.

tomography (CT) scan (Somatom Sensation 16, Siemens, Erlangen, Germany) revealed a huge, relatively well defined, heterogeneously hypodense mass, most of which showed minimal enhancement with multifocal low attenuated areas ( -15 to -40 Hounsfield unit). The mass was located in the retropharyngeal space extending to both lateral sides of the neck. The tumor displaced but did not infiltrate the adjacent structures (Fig. 1B). The maximum dimensions of the entire tumor were $10 \times 5 \times 11 \mathrm{~cm}$. There was no evidence of associated cervical lymphadenopathy. $0 \mathrm{n}$ magnetic resonance imaging (3.0 Tesla, Verio, Siemens Medical Solution, Erlangen, Germany), most of the mass showed heterogeneously hypointense signal intensity on T1-weighted image (WI) (repetition time $[T R]=750$, echo time $[\mathrm{TE}]=9.5)$ and hyperintense signal intensity on fat saturated T2WI $(T R=3950, T E=89)$. There were multifocal areas of high signal intensity within the tumor on T1WI, which showed signal loss on fat saturated T2WI (Fig. 1C, D). The tumor extended up to the soft palate level cranially and the thoracic inlet level caudally on sagittal T2WI (TR = $3200, \mathrm{TE}=99)($ Fig. 1E). After gadolinium administration $(0.1 \mathrm{mmol} / \mathrm{kg}$ of body weight, omniscan (gadodiamide), GE Healthcare, Oslo, Norway), the mass showed heterogeneous enhancement (Fig. 1F, G).

The mass was extirpated by the transcervical approach without complications and was easily separated from the adjacent structures. The patient had immediate amelioration of dysphagia and other symptoms after the operation. The surgical specimen showed a well-circumscribed and lobulated mass with a thin fibrous capsule (Fig. 1H). On histologic examination, the tumor showed mostly spindle shaped cells in a collagenous background. Mature adipose tissue and characteristic floret-like multinucleated cells were also present between the spindle cells (Fig. 1I). Immunohistochemical staining for CD34 was positive in the spindle shaped cells (Fig. 1J) and staining for S-100 protein was positive in the mature fat cells (Fig. $1 \mathrm{~K}$ ).

\section{DISCUSSION}

Lipomas are one of the most common soft tissue tumors, which are classified into various subtypes, namely fibrolipoma, angiolipoma, myxoid lipoma, spindle cell lipoma, pleomorphic lipoma, and chondroid lipoma (3). Although spindle cell lipoma and pleomorphic lipoma have been classified as discrete variants of benign adipose tissue tumor in the past, they are now considered to be the same entity because of their overlapping clinical, histological, immunohistochemical, and cytogenetic features (4, 5-7).

Spindle cell/pleomorphic lipoma is an uncommon tumor, usually occurring as well-demarcated subcutaneous mass in middle-aged or elderly men, and in the posterior head and neck, but also in the shoulder and back. Spindle cell/ pleomorphic lipomas are generally presented as a solitary, soft and slowly enlarging mass, with a variable size measuring 1-13 cm $(1,5)$. Cytogenetically, most spindle cell/pleomorphic lipomas show 16q or 13q abnormalities $(6,7)$. The treatment of choice for spindle cell/pleomorphic lipoma is a complete local excision and its recurrence is extremely rare. Some authors have reported on the intradermal origin of spindle cell/pleomorphic lipoma which presents with distinct clinical or morphological features such as female predilection, wider anatomical distribution, and an infiltrative pattern $(1,2,5)$. 

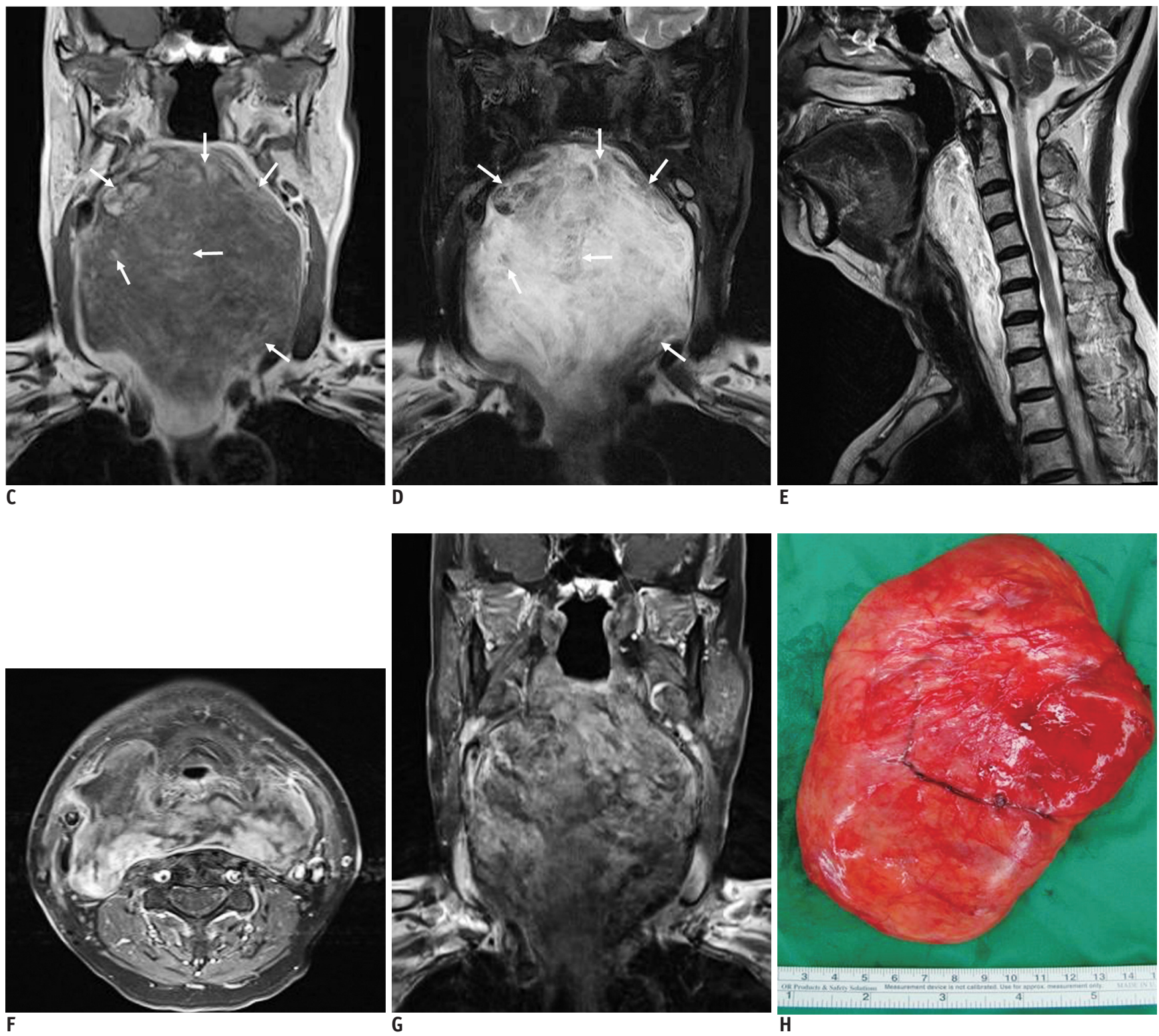

Fig. 1. Retropharyngeal spindle cell/pleomorphic lipoma in 69-year-old woman.

C-G. On magnetic resonance imaging, mass is observed to have diffusely hypointense signal on T1-weighted image (WI) (C) and hyperintense signal on fat saturated T2WI (D). There are multifocal areas of high signal intensity within mass on T1WI which showed signal loss on fat saturated T2WI (arrows). Mass extends up to soft palate level cranially and thoracic inlet level caudally on sagittal T2WI (E). Fat saturated gadolinium-enhanced axial (F) and coronal (G) T1WI show exceedingly heterogeneous enhancing mass. H. Surgical specimen shows wellcircumscribed and lobulated mass with thin fibrous capsule.

The imaging findings of spindle cell lipoma have been presented in some scattered case reports and original articles. Bancroft et al. (8) reported that the appearance of spindle cell lipoma in imaging studies is variable and not pathognomonic for diagnosis as the variation in the ratio of adipose and non-adipose components causes a wide spectrum of imaging features. These features may mimic liposarcoma. However, previously reported cases on the appearance of spindle cell/pleomorphic lipoma in radiological imaging studies are extremely rare. We were able to find only one case report of the spindle cell/ pleomorphic lipoma which included imaging findings. Gu et al. (4) reported a case of spindle cell/pleomorphic lipoma originating from the oropharynx, and briefly mentioned the CT imaging finding of a low density mass in the area of the left vallecula and pyriform sinus extending to the aryepiglottic fold. The CT and MR imaging findings in the present study are compatible with those of spindle cell lipoma reported by Bancroft et al. (8). Although the possibility of fat containing tumors was considered 


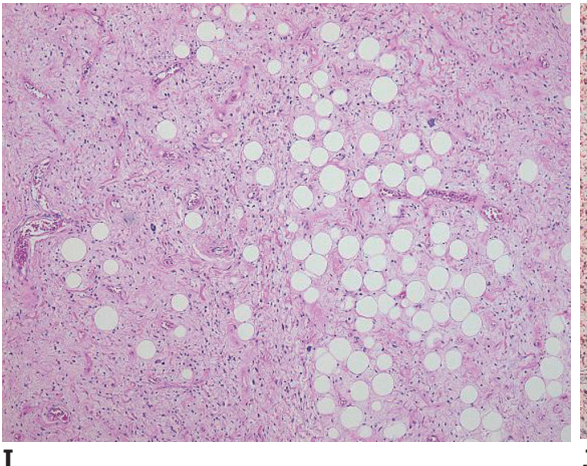

Fig. 1. Retropharyngeal spindle cell/pleomorphic lipoma in 69-year-old woman.

I. Most of tumor contains spindle shaped cells in collagenous background. Between spindle cells, mature adipose tissue and characteristic floretlike multinucleated cells are present (Hematoxylin \& Eosin staining; original magnification, $\times 10$ ). J. Spindle tumor cells are positive for CD34 (immunohistochemical staining; original magnification, $\times 10$ ). K. Mature fat cells are positive for S-100 protein. In contrast, spindle cells have no immunoreactivity for S-100 protein (immunohistochemical staining; original magnification, $\mathrm{x} 10$ ).

based on the imaging findings, we could not distinguish between liposarcoma and lipoma variants with information from location and imaging appearances of the tumor, and therefore were unable to make a diagnosis prior to surgery.

Regarding the retropharyngeal space anatomy, the retropharyngeal space contains lymph nodes and fatty tissues. The clinical significance of the retropharyngeal space is related to the potential spread of infection and malignancy. In the differential diagnosis of non-infectious retropharyngeal lesions, most of these abnormalities are malignant lesions such as direct invasion or nodal metastases from head and neck cancer (9). In the case of our patient, the tumor was thought to arise from retropharyngeal adipose tissue and to extend to the parapharyngeal space and lateral neck compartment. Primary neoplasms originating in the retropharyngeal space should therefore be considered in the differential diagnosis in spite of the extremely rare incidence.

Histologically, spindle cell/pleomorphic lipoma may display diverse histologic features depending on the proportion of cellular components. Also, the differential diagnoses can be altered according to predominant histologic components $(1,2,4,5)$.

In conclusion, we present here the first case of retropharyngeal spindle cell/pleomorphic lipoma with imaging findings. On CT scan, the tumor appeared as a well-marginated, mild enhancing mass with multifocal hypoattenuated portions corresponding to fat density. On T1WI and T2WI, the tumor showed mixed signal intensity, which may reflect the proportion of adipose and nonadipose tissues. After the intravenous administration of gadolinium-based contrast material, the tumor showed heterogeneously intense enhancement. Although these imaging findings are not pathognomonic, spindle cell/pleomorphic lipoma should be considered in the differential diagnoses of fat-containing mass involving the retropharyngeal space.

\section{REFERENCES}

1. French CA, Mentzel $T$, Kutzner $H$, Fletcher CD. Intradermal spindle cell/pleomorphic lipoma: a distinct subset. Am J Dermatopathol 2000;22:496-502

2. Reis-Filho JS, Milanezi F, Soares MF, Fillus-Neto J, Schmitt FC. Intradermal spindle cell/pleomorphic lipoma of the vulva: case report and review of the literature. J Cutan Pathol 2002;29:59-62

3. Vecchio G, Amico P, Caltabiano R, Colella G, Lanzafame S, Magro G. Spindle cell/pleomorphic lipoma of the oral cavity. J Craniofac Surg 2009;20:1992-1994

4. Gu MJ, Sohn KR, Park JH. Spindle cell/pleomorphic lipoma of the oropharynx. Korean J Pathol 2009;43:580-582

5. Gurel D, Kargi A, Lebe B. Pedunculated cutaneous spindle cell/pleomorphic lipoma. J Cutan Pathol 2010;37:e57-e59

6. Dal Cin P, Sciot R, Polito P, Stas M, de Wever I, Cornelis A, et al. Lesions of $13 q$ may occur independently of deletion of $16 q$ in spindle cell/pleomorphic lipomas. Histopathology 1997;31:222-225

7. Mandahl N, Mertens F, Willén H, Rydholm A, Brosjö 0, Mitelman F. A new cytogenetic subgroup in lipomas: loss of chromosome 16 material in spindle cell and pleomorphic lipomas. J Cancer Res Clin Oncol 1994;120:707-711

8. Bancroft LW, Kransdorf MJ, Peterson JJ, Sundaram M, Murphey MD, O'Connor MI. Imaging characteristics of spindle cell lipoma. AJR Am J Roentgenol 2003;181:1251-1254

9. Chong VF, Fan YF. Radiology of the retropharyngeal space. Clin Radiol 2000;55:740-748 